\title{
OS ANTECEDENTES DA ORIENTAÇÃO EMPREENDEDORA NO CONTEXTO DOS NEGÓCIOS SOCIAIS
}

Viviane Celina Carmona ${ }^{1}$

Cristina Dai Pra Martens ${ }^{1}$

Henrique Mello Rodrigues De Freitas ${ }^{1}$

${ }^{1}$ PPGA Administração / UNINOVE / Universidade Nove de Julho 


\section{OS ANTECEDENTES DA ORIENTAÇÃO EMPREENDEDORA NO CONTEXTO DOS NEGÓCIOS SOCIAIS}

Resumo: A Orientação Empreendedora (OE) se refere ao empreendedorismo no nível organizacional. Este artigo tem como objetivo caracterizar os Antecedentes da OE em Startups de Negócios Sociais. Os Negócios Sociais possuem como propósito principal minimizar os problemas sociais, gerando impacto social de maneira autossustentável. Para o alcance dos objetivos deste artigo, foi desenvolvido um estudo exploratório e qualitativo, com coleta de dados por meio de entrevistas semiestruturadas, feitas a fundadores de oito negócios sociais. No contexto social, a identificação de oportunidades é caracterizada por antecedentes diferentes do contexto puramente comercial. Os resultados mostram que a missão social é vista como uma oportunidade por empreendedores destes negócios sociais que buscam ofertar produtos e serviços não apenas à população carente, e sim estão buscando contribuir para a qualidade de vida da população em geral. Destacam-se os antecedentes da OE motivação social / missão e identificação de oportunidades.

Palavras-chave: Antecedentes. Orientação Empreendedora. Negócios Sociais. Startups.

\section{Introdução}

Este artigo trata sobre a Orientação Empreendedora (OE) de Negócios Sociais (NS). Comparações e contrastes entre o empreendedorismo comercial e o empreendedorismo social são discussões presentes na literatura, apresentando algumas dimensões, sugerindo que os antecedentes da OE diferem diante de um contexto social. Porém pouco se sabe sobre os processos empresariais sociais e se há diferenças entre negócios comerciais e sociais (Lumpkin et al., 2013).

Vistos como um campo de oportunidade para pesquisas, estudos sobre negócios sociais e orientação empreendedora crescem nos últimos anos, junto aos estudos sobre empreendedorismo social, que vêm atraindo a atenção como assunto frequente (Short, Ketchen, Combs, \& Ireland, 2010). A OE trata do estudo do empreendedorismo da organização e pode influenciar positivamente o desempenho de uma organização, apontando para o fato que organizações com maior OE tendem a ser mais bem-sucedidas que organizações com uma menor OE (Miller, 1983; Covin \& Slevin, 1991; Zahra \& Covin, 1995; Wiklund \& Shepherd, 2005; Keh et al., 2007; Naldi et al., 2007; Li, 2009).

Uma vez que a OE tem impacto positivo nas medidas de desempenho financeiro, se positivamente associada ao crescimento, pode ser considerada benéfica para as organizações, podendo assim facilitar a descoberta de novas oportunidades, habilitando a diferenciação e a criação de vantagem competitiva (Wiklund \& Shepherd, 2003; Martens \& Freitas, 2010).

Partindo da importância de investigar os antecedentes da Orientação Empreendedora em um contexto específico, este artigo tem como objetivo caracterizar os antecedentes da
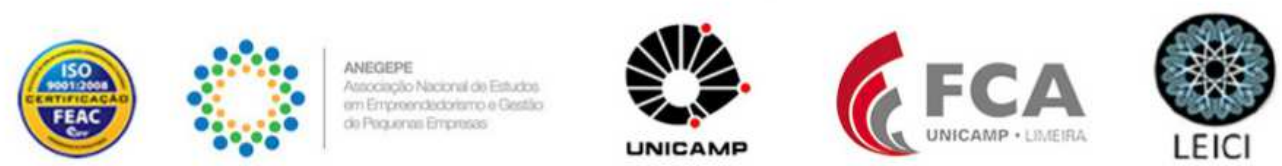
orientação empreendedora em negócios sociais. Assim, foi organizado da seguinte forma: na seção 2 é feita uma breve revisão conceitual sobre a OE e sobre os Negócios Sociais, na seção 3 são apresentados os antecedentes da orientação empreendedora em contexto social, em seguida, na seção 4 o método de pesquisa utilizado no estudo; na seção 5 são tratados os resultados da pesquisa, apresentando um breve panorama teórico sobre os antecedentes da $\mathrm{OE}$; na seção 6 são apresentadas as considerações finais, tendendo a contribuir para o debate sobre os negócios sociais.

\section{A Orientação Empreendedora (OE) e os Negócios Sociais (NS)}

A OE é o empreendedorismo de um negócio (Martens \& Freitas, 2010). Está associada positivamente ao crescimento de um empreendimento, podendo também cooperar com a competência de encontrar novas oportunidades (Wiklund \& Shepherd, 2003). Com um olhar estratégico, a OE surge da oportunidade de novos negócios que podem ser empreendidos com sucesso, de forma prudente, em um processo dinâmico envolvendo ações determinadas (Lumpkin \& Dess, 1996; Martens \& Freitas, 2010).

Diversos estudos têm focado em dimensões que caracterizam a OE. Três dimensões: inovatividade, assunção de riscos e proatividade, foram propostas por Miller (1983) para caracterizar e testar o empreendedorismo nas organizações. A partir dos estudos de Miller (1983), os pesquisadores Lumpkin e Dess (1996) apresentaram outras duas dimensões para caracterizar e diferenciar o processo empreendedor: autonomia e agressividade competitiva.

As pesquisas sobre empreendedorismo têm adotado a OE como instrumento para ampliar e enriquecer o conhecimento na área ( Morris, Webb \& Franklin, 2011). Ainda de acordo com os autores Morris et al. (2011), para a compreensão do empreendedorismo e da aplicação da OE, devem ser considerados três importantes indicadores: a motivação, atrelada às oportunidades vinculadas à necessidade de servir a um propósito social; os processos, são as motivações baseadas na missão social e se diferenciam em seus processos; e os resultados, que são indicadores sociais e financeiros que servem como métricas de desempenho. A maior parte dos estudos sobre OE aplicada a organizações sem fins lucrativos tem adotado apenas três dimensões da OE: inovatividade, proatividade e assunção de riscos (Morris, Webb \& Franklin, 2011). Complementando estes estudos, propõe-se, no presente artigo, o modelo para estudo de seis dimensões da OE, seus antecedentes e resultados.

A proposição de modelos específicos de caracterização das dimensões da $\mathrm{OE}$ foi apontada por Morris, Webb \& Franklin, (2011), afirmando que ao generalizar as dimensões da OE e suas características pode-se perder elementos fundamentais em um campo de estudo especifico. Reconhecer as dimensões da OE pode contribuir com o desempenho dos negócios sociais, tendo em vista ser esse um novo campo de estudo que ainda carece de desenvolvimento (Barki et al., 2015).

Os negócios sociais são um híbrido do segundo e terceiro setor da economia, priorizando o impacto social e equilibrando a autossustentabilidade financeira (Rosolen; Tiscoski \& Comini, 2014). A criação de valor social é a principal motivação, mas é necessário criar valor econômico além do impacto social para assegurar a viabilidade financeira (Mair \& Marti, 2006), assim, é possível afirmar que o a geração de valor econômico é fundamental para a

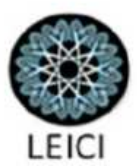


sustentabilidade dos negócios sociais, obviamente que o mesmo deve estar em equilíbrio com o valor social gerado (Dacin, Dacin \& Matear, 2010; Muñoz \& Kibler, 2015).

Administrar um empreendimento onde coexistem o interesse social e o econômico simultaneamente muitas vezes é complexo, pois são objetivos muitas vezes conflituosos. Vale ainda ressaltar que um negócio social se difere de ações filantrópicas ou ONGs (Organizações Não Governamentais) ou OSCIP (Organizações da Sociedade Civil de Interesse Público): negócios sociais são empresas cujos resultados devem incorporar a geração de valor, ou a geração de impacto social e que os proprietários podem recuperar os seus investimentos (Comini, 2011).

O caminho para analisar os resultados pode passar pelo gerenciamento empreendedor, também chamado de $\mathrm{OE}$ onde a gestão está refletida nos processos organizacionais, métodos e estilos que uma organização adota para ser empreendedora (Stevenson \& Jarillo, 1990). O referencial teórico sobre a OE vem sendo utilizado para preencher essa importante lacuna na literatura sobre a prática do empreendedorismo nas organizações (Covin \& Lumpkin, 2011), e será melhor detalhado a seguir.

\section{Os Antecedentes da Orientação Empreendedora em Contexto Social}

A definição de empreendedor é ampla e não consensual, porém muitos pesquisadores afirmam que os empreendedores têm características singulares, que as diferem das demais pessoas (Wortman, 1986; Gartner, 1988; Cooley, 1990), características estas que podem ser desenvolvidas e treinadas (Mcclelland, 1987; Ross, 1987; Salte, 1989; Cooley, 1990; Fillion, 1993; Hornsby et al., 1993; Timmons et al., 1999; Fillion, 2000). Para caracterizar o empreendedor não há perfis que sigam um único padrão, considerado como uma fórmula mágica, não há procedimentos prontos ou uma receita, o perfil de um empreendedor está atribuído ao resultado da sua interação pessoal com o empreendimento e o ambiente externo (Sathe , 1989) evidenciando que eventos externos ou internos como o desenvolvimento de novas tecnologias, mudança na demanda do consumidor e mudanças econômicas influenciam as características do empreendedor (Hornsby et al., 1993).

A literatura sobre empreendedorismo social aponta algumas características de antecedentes para o contexto, divididas em quatro classificações, são elas: 1 - motivação social / missão, 2 - identificação de oportunidades, 3 - o acesso ao capital / financiamento, e 4 - várias partes interessadas, os stakeholders (Lumpkin et al., 2013). O antecedente denominado motivação social / missão (Lumpkin et al., 2013). Está relacionado às motivações de um negócio social, que são coletivas e priorizam os objetivos sociais, que estão focadas nas necessidades e desejos individuais e tendências de consumo, além das necessidades humanas, contraposta pelas missões de organizações puramente comerciais. A motivação é a base da ação individual ou da missão organizacional, sendo o antecedente que mais objetivamente distingue o empreendedor social de outros empreendedores. A missão está concentrada em problemas e necessidades sociais presentes há muito tempo na sociedade, como a fome, a pobreza, a falta de habitação, a violência, a poluição, ausência de atendimento médico, problemas no âmbito educacional e outros, portanto são amplamente conhecidas, assim sendo, podem ser consideradas como uma oportunidade de problema a ser resolvido (Lumpkin et al., 2013).
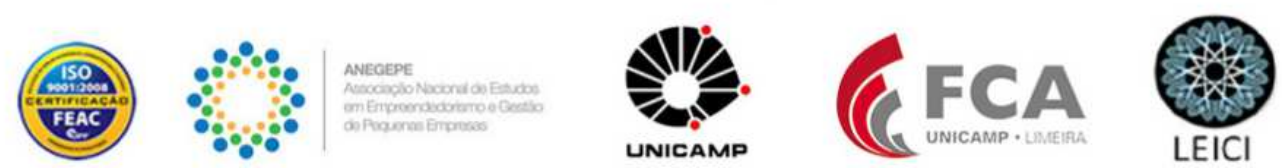
Outro antecedente presente na literatura de empreendedorismo social é a identificação de oportunidades (Lumpkin et al., 2013). A identificação de oportunidade é essencial para o desenvolvimento de um empreendimento e normalmente está associada a oportunidade de obtenção de lucro. A resolução de problemas sociais, no contexto dos negócios sociais é considerada uma oportunidade, sendo assim, o empreendedorismo pode ser uma fonte de soluções transformadas em oportunidades. Estas oportunidades estão especificamente direcionadas a populações carentes ou desfavorecidas, e a aplicação de soluções empresariais para solucionar um problema social depende da percepção sobre os valores sociais e do nível de recursos que os empreendedores sociais podem mobilizar, sendo o apoio financeiro e comunitário à iniciativa, e a mobilização da população indicadores chave que indicam que o reconhecimento das oportunidades (Lumpkin et al., 2013).

Apesar de não ser uma característica distintiva, quando comparada a qualquer empresa ou empresário em início de operação, o acesso ao capital / financiamento é também um dos antecedentes dos negócios sociais a ser observado, já que aborda a limitação de recursos e a dificuldade em adquirir capital para iniciar ou dar continuidade ao negócio, evidenciando a dificuldade de acesso ao capital quando não há boas perspectivas de geração de fluxo de caixa (Lumpkin et al., 2013). Assim sendo, há ainda outro movimento a ser evidenciado que se refere a competição direta por recursos e apoio de consumidores conscientes existente entre as empresas consideradas puramente comerciais e as empresas sociais (Lumpkin et al., 2013).

O seguinte antecedente da Orientação Empreendedora a ser analisado são as várias partes interessadas - os chamados stakeholders (qualquer indivíduo ou grupo que é afetado ou que pode afetar a capacidade de uma organização para atingir seus objetivos). Em ambientes comerciais, os stakeholders são os investidores, empregados, fornecedores e compradores de bens e serviços, são necessários para o sucesso do empreendimento e são, portanto, as partes interessadas mais influentes porque têm uma participação financeira no negócio. Pode ser um grupo de apoiadores que têm interesse no sucesso da empresa na sua missão social. (Lumpkin et al., 2013). Há ainda outros grupos, outros stakeholders como cidadãos locais, agências governamentais ou a comunidade na qual o empreendimento opera. Além disso, as estruturas de propriedade social que incluem clientes, usuários e grupos locais ou comunitários ou trustes, lhes concedem poder e legitimidade, bem como maiores oportunidades para apresentar a urgência de suas reivindicações, o que pode alterar diretamente as operações do empreendimento (Lumpkin et al., 2013). Para facilitar a compreensão, foi criada a Figura 1, com as categorias dos antecedentes da $\mathrm{OE}$ e a sua descrição, sintetizando as informações apresentada nesta seção.

Figura 1 - Categorias dos Antecedentes da Orientação Empreendedora em Negócios Sociais

\begin{tabular}{|c|c|c|}
\hline \multirow{4}{*}{ 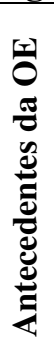 } & Categorias & Descrição \\
\hline & Motivação social / missão & $\begin{array}{l}\text { As motivações são a base organizacional, devem ser voltadas ao } \\
\text { coletivo e priorizar os objetivos sociais. A missão é o antecedente } \\
\text { mais distintivo do empreendedor social de outros empreendedores. }\end{array}$ \\
\hline & $\begin{array}{l}\text { Identificação de } \\
\text { oportunidades }\end{array}$ & $\begin{array}{l}\text { Os NS consideram uma oportunidade a resolução de problemas } \\
\text { sociais. }\end{array}$ \\
\hline & $\begin{array}{l}\text { O acesso ao capital / } \\
\text { financiamento }\end{array}$ & $\begin{array}{l}\text { Acesso a recursos financeiros. O acesso é dificultado se não houver } \\
\text { boas perspectivas de geração de fluxo de caixa. }\end{array}$ \\
\hline
\end{tabular}

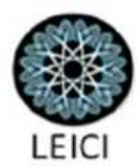




\begin{tabular}{|c|c|c|}
\hline $\begin{array}{c}\text { Várias partes interessadas, os } \\
\text { stakeholders }\end{array}$ & $\begin{array}{l}\text { São indivíduos ou grupos que são influenciados ou que podem afetar } \\
\text { a capacidade de uma organização para atingir seus objetivos. }\end{array}$ \\
\hline
\end{tabular}

Fonte: Elaborada pelos autores, baseado em Lumpkin et al., 2013

As categorias e as suas descrições exibidas na Figura 1 serão exploradas em profundidade na análise dos resultados apresentados na seção cinco.

\section{Métodos e procedimentos de coleta dos dados}

Buscando caracterizar os antecedentes da OE em Negócios Sociais, este estudo tem caráter descritivo e exploratório ao procurar compreender o fenômeno e indicar novas ideias ou hipóteses a serem testadas (Rudio, 1986). O estudo teve início com uma pesquisa bibliográfica, ponto de partida para a pesquisa científica, pois o levantamento é necessário para que o pesquisador obtenha mais informações sobre o fenômeno que pretende investigar.

Este é um estudo qualitativo realizado por meio de entrevistas semiestruturadas que é uma técnica de coleta de dados que permite a captação de dados subjetivos, como as motivações, os valores os significados e as crenças que não são descobertos facilmente com pesquisas quantitativas, por se tratar de situações e fatos muito particulares (Boni \& Quaresma, 2005). O roteiro de entrevistas foi elaborado com base na literatura, partindo do modelo teórico para estudo de processos empresariais em contextos sociais, de Lumpkin et al., (2013), apresentado na Figura 2 a seguir.

Figura 2 - Antecedentes únicos para o contexto ES

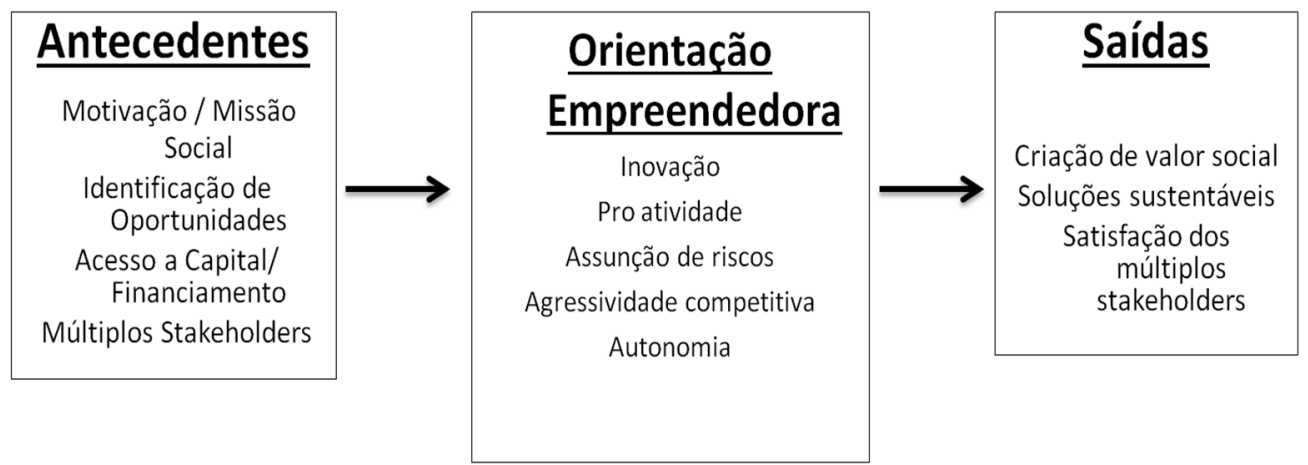

Fonte: Adaptado de Lumpkin et al., 2013

O modelo teórico de Lumpkin et al., (2013) foi desenvolvido para empreendimentos sociais em geral, não especificamente para os negócios sociais e não foi testado empiricamente. Aqui o que se pretende é diverso, à medida que está focando em um ponto único que são os negócios sociais, buscando validar e ampliar o modelo existente. Diante da escolha de estudar os antecedentes da OE de empreendedores sociais, percebeu-se uma dificuldade em definir quais empreendedores sociais seriam o foco desta pesquisa, e dentre as diferentes tipologias, a opção escolhida foi investigar os negócios sociais, que atraem particularmente o interesse dos autores por combinar a criação de valor social e autossustentabilidade, contrapondo ideias gerais de filantropia e doações comumente presentes nos empreendimentos sociais. 
A entrevista semiestruturada foi elaborada de maneira a facilitar a compreensão sobre os antecedentes da OE. A entrevista tem o papel de complementar os dados bibliográficos, pois permite coletar dados objetivos e subjetivos (Boni \& Quaresma, 2005). Para assegurar que o roteiro atende aos objetivos desta pesquisa, foi aplicado um pré-teste com três gestores de negócios sociais, para que fossem feitos ajustes e correções, assim como, para calcular o tempo estimado para realização. Como foram entrevistados empreendedores que estão por todo o Brasil, foram utilizadas outras ferramentas, como o software Skype, para as chamadas e videoconferências, e-mails, telefone, o software Microsoft Excel para organizar as planilhas e informações e gravadores de som e o software Atlas TI para a análise de conteúdo.

As entrevistas foram transcritas e analisadas uma a uma, com auxílio do software Atlas TI, marcando os indícios dos antecedentes em suas quatro categorias, sendo elas: motivação e missão social; identificação de oportunidades; várias partes interessadas - os stakeholders; e, o acesso ao capital e financiamento. As falas dos empreendedores que representavam cada um dos antecedentes foram marcadas para facilitar a análise e caracterização individual, ou seja, por dimensão e de maneira coletiva, gerando a Figura 4 (que será apresentada na seção de análise de resultados), que permite comparações.

Os oito empreendimentos que compõem o contexto desta pesquisa são caracterizados na Figura 3.

\section{Figura 3 - Breve descrição dos empreendimentos analisados}

\begin{tabular}{|c|c|c|}
\hline & Empresa & Breve descrição do Negócio Social \\
\hline NS1 & $\begin{array}{l}\text { Alimentação e Educação } \\
\text { São Paulo -SP }\end{array}$ & $\begin{array}{l}\text { É um negócio social que combina agricultura urbana e educação alimentar } \\
\text { para promover saúde e bem-estar na cidade. Buscam transformar espaços } \\
\text { ociosos em espaços produtivos com hortas. }\end{array}$ \\
\hline NS2 & $\begin{array}{l}\text { E-commerce - Shopping para } \\
\text { Lojistas } \\
\text { Curitiba - PR }\end{array}$ & $\begin{array}{l}\text { Trata-se de um Marketplace com a maior comunidade de lojistas do Brasil. } \\
\text { Possui boa reputação, grande volume de avaliações mensais, visibilidade e } \\
\text { o melhor ranqueamento. }\end{array}$ \\
\hline NS3 & $\begin{array}{l}\text { Educação empreendedora } \\
\text { com impacto social e } \\
\text { ambiental } \\
\text { São Paulo - SP } \\
\text { Atende todo o Brasil }\end{array}$ & $\begin{array}{l}\text { Trabalha a educação empreendedora com foco em negócios de impacto } \\
\text { social. Sua fundadora já participou de competição mundial de projeto de } \\
\text { impacto representando o Brasil na Guatemala, em } 2013 \text {, sendo uma das } 8 \\
\text { finalistas de } 1600 \text { projetos. Ganhou o prêmio Jovem de Empreendedorismo. } \\
\text { E foi uma das } 10 \text { finalistas do Prêmio de Empreendedorismo Roberto Justus. } \\
\text { Representou o Brasil no encontro do G20, na China em } 2017 \text {, atuando em } \\
\text { dois temas principais: Empreendedorismo e Sustentabilidade. }\end{array}$ \\
\hline NS4 & $\begin{array}{l}\text { Finanças - plataforma de } \\
\text { pagamentos via celular } \\
\text { Marilia - SP } \\
\text { Atende todo o Brasil }\end{array}$ & $\begin{array}{l}\text { É a primeira solução de pagamento de vale alimentação e vale refeição via } \\
\text { celular homologado no PAT (Programa de Alimentação do Trabalhador). } \\
\text { Desenvolvem soluções que vão desde a inclusão financeira da população } \\
\text { sem acesso à contas bancárias até uma plataforma completa para gestão de } \\
\text { benefícios trabalhistas. }\end{array}$ \\
\hline NS5 & $\begin{array}{l}\text { Capacitação para NS } \\
\text { Rio de Janeiro e São Paulo - } \\
\text { Atende todo Brasil }\end{array}$ & $\begin{array}{l}\text { Atua na capacitação de empreendedores sociais oferecendo metodologia } \\
\text { própria para proporcionar inovação dentro das empresas. }\end{array}$ \\
\hline NS6 & $\begin{array}{l}\text { Infraestrutura Urbana } \\
\text { São Paulo - SP }\end{array}$ & $\begin{array}{l}\text { Empreendimento referência em brinquedos e equipamentos de lazer de } \\
\text { pequeno, médio e grande portes, que trazem a brasilidade em seus formatos } \\
\text { e cores para espaços públicos e privados, parte do urbanismo } \\
\text { contemporâneo através de interações no cotidiano. }\end{array}$ \\
\hline
\end{tabular}


NS7 Saúde - Plataforma on line para médicos e pacientes. Rio de janeiro - RJ e Bélgica - Atende todo o Brasil

NS8 Soluções em tecnologia e que geram experiências. São Paulo -SP
É a primeira plataforma brasileira na área da saúde educativa e personalizada, que dá orientações e faz o monitoramento remoto envolvendo os pacientes, e coordenando seus cuidados com inteligência e tecnologia gerando bases de dados.

Buscam criar e identificar soluções de impacto que sejam implantadas e replicadas em diferentes contextos, organizações e regiões, clientes e parceiros.

Fonte: Elaborado pelos autores, com base nas entrevistas

Como pode ser observado, a pesquisa foi aplicada a startups de negócios sociais diversos, que foram selecionados por terem sido incubados por uma organização pioneira na disseminação e no fomento desse tipo de negócios no Brasil. A incubadora foi escolhida por ser referência nacional e ter critérios bem definidos quanto à escolha dos negócios a serem incubados, e por ter sido apontada como a aceleradora de maior destaque em pesquisa recente com negócios sociais (Petrini, Scherer, \& Back, 2016), seguindo a premissa de Bourdieu (1999) sobre a necessidade de escolher bem a amostra, por meio de critérios bem definidos. A incubadora possui em seu portfólio cerca de 80 negócios acelerados nos últimos 3 anos; todos foram contatados por e-mail e 8 foram respondentes da entrevista, selecionados por terem vivenciado o fenômeno principal deste estudo (Creswell, 2010) e por terem aceito participar.

A seleção dos empreendimentos está alinhada com a contextualização do problema a ser estudado, suportada pelo referencial teórico, que se refere aos processos estudados na literatura sobre $\mathrm{OE}$, empreendedorismo social, e negócios sociais. Os fundadores foram os participantes das entrevistas uma vez que possuem conhecimento especializado de atuação em negócios sociais (Hair, 2007). Vale destacar, também, que os casos de negócios sociais foram escolhidos para ampliar a teoria, ou para preencher categorias teóricas (Eisenhardt, 1989).

\section{Análise dos Resultados}

O perfil dos entrevistados mostrou que a maioria destes empreendedores são jovens entre 25 e 34 anos de idade, com formação superior, pós-graduação e altamente qualificados quanto ao assunto negócios sociais. Um panorama geral do que pensam esses empreendedores sociais (com base nas entrevistas realizadas) pode ser ilustrado da seguinte forma: esses empreendedores sociais não estão buscando doações e não querem ser agentes filantropos; eles desejam mudar a realidade de uma região, de um país e mudar o mundo. Usam seus conhecimentos e experiências na expectativa de viverem melhor, e terem um emprego, um cargo, uma função, uma tarefa que faça sentido; assim criam ambientes de trabalho diverso daqueles chamados tradicionais, daqueles em que atuaram anteriormente e não viam sentido, por atuarem de maneira parecidas com verdadeiras linhas de produção industrial e com horários rígidos de entrada e sem horário para saída, o que os entrevistados apontam como espaço improdutivo, que geram insatisfação e frustrações.

Com base nas respostas dos entrevistados, e com o uso do software Atlas TI, foi gerada a Figura 4 para caracterizar os antecedentes da OE em NS, em suas categorias identificação de oportunidades, motivação social/missão, acesso ao capital/financiamento e várias partes interessadas (stakeholders). O gráfico mostra que dos quatro antecedentes do contexto social 
estudados, a missão social e a identificação de oportunidades são igualmente consideradas as mais importantes.

\section{Figura 4 - Caracterização dos Antecedentes da OE em Negócios Sociais}

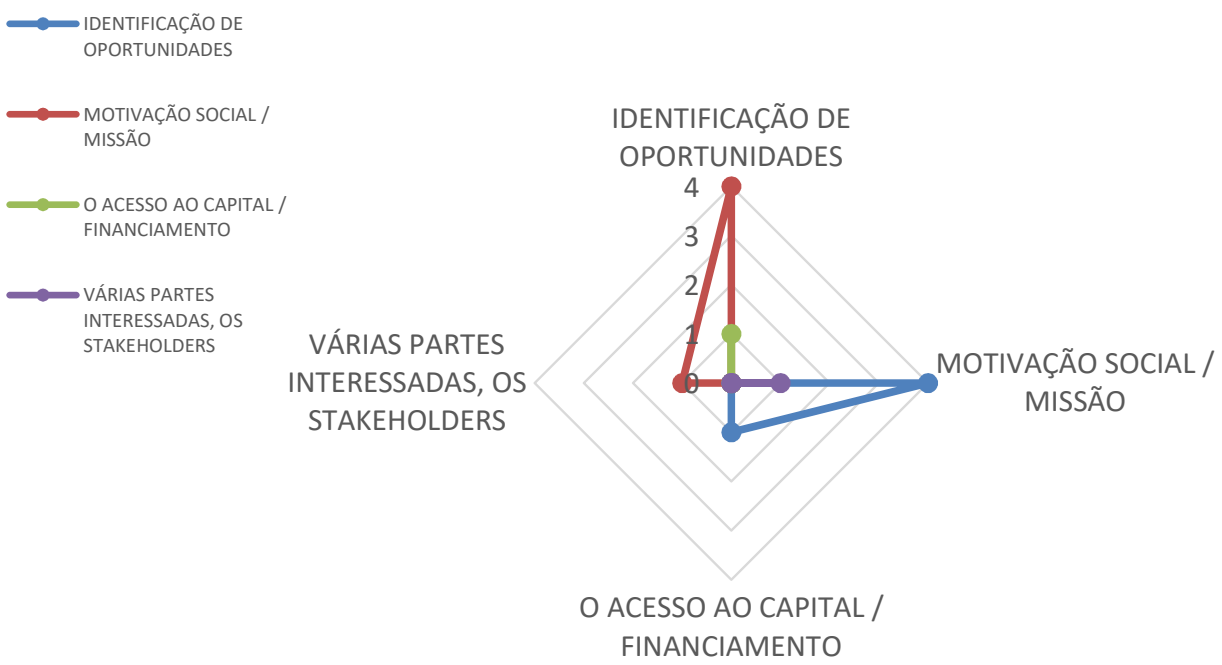

Fonte: Elaborada pelos autores, com dados da pesquisa, no software Atlas TI.

A seguir serão detalhados os resultados dos antecedentes da OE divididos nas quatro categorias.

\subsection{Motivação social e missão}

Entre os motivos para empreender há destaque para aqueles que preferem depender das próprias habilidades para a obtenção de resultados, buscando a realização por meio da dedicação e da assunção de riscos ao assumir tarefas desafiadoras (Mcclelland, 1972). A motivação é uma das características observadas em empreendedores exitosos, e estão atribuídas à persistência e comprometimento com o trabalho (Mansfield et al., 1987).

A principal motivação desses fundadores de Negócios Sociais entrevistados é o impacto social, que é visto como oportunidade, tanto para a resolução de problemas sociais como oportunidade de negócio lucrativo.

NS2 - "empresa criada com a missão de tornar-se o maior marketplace para artesãos no Brasil. Ao perceber que a dificuldade de acessar as grandes redes varejistas do país não se restringia apenas aos artesãos, criou-se a nova empresa em 2015 com a missão de ajudar todo e qualquer lojista a chegar aos maiores e melhores marketplaces nacionais e internacionais."

Em um momento em que os jovens estão procurando gerar "negócios com propósito", (a expressão do momento) eles conseguem ver propósito ao desenvolverem negócios que podem mudar o mundo.

NS1 - "tava sentindo falta de ter um impacto mais direto, porque a gente trabalhava muito com estratégia e a estratégia sempre depende da empresa implantar ou não. E ele queria fazer uma coisa mais mão na massa." 
NS6 - " a ideia surgiu num momento de crise existencial mesmo, quando eu estava fazendo cenografia. Eu sempre tive um trabalho muito forte ligado ao social. Antes de eu ir para a cenografia, eu sou formado em artes plásticas, sou artista plástico, acabei em um momento, que eu falei, cara, quer saber? eu vou voltar para continuar este trabalho de parte social, que me move"

A insatisfação com o emprego anterior, a postura dos chefes e suas cobranças por resultados, assim como um país com diversos problemas sociais negligenciados pelo poder público, e não satisfatoriamente atendidos pelo terceiro setor, são apontados como as principais motivações dos empreendedores entrevistados.

NS3 - "Eu comecei com a ideia de um projeto de Iniciação Científica que eu fazia, que era transformar óleo em biodiesel, e aí foi a primeira vez que eu saí representando o Brasil em uma competição mundial... Eu não ganhei o primeiro lugar nesse prêmio da Guatemala, mas eu fui uma das 8 finalistas de 1600 projetos. E aí quando eu voltei, eu consegui ganhar uma bolsa de estudos na Fundação Cabral, que estava formando a primeira turma de um programa que eles têm, que é chamado Dignidade, que é voltado para negócios sociais."

\subsection{Identificação de oportunidades}

A habilidade para identificar oportunidades é destaque entre as pesquisas sobre características empreendedoras, lançando a necessidade de antecipação forçadamente ou devido às circunstâncias por parte dos empreendedores (COOLEY, 1990).

A oportunidade de mudar a sociedade é apontada nas entrevistas como o fator decisivo no momento da criação do negócio, pois os negócios foram fundados com a percepção de que as necessidades sociais são lacunas a serem preenchidas, e com isso buscam não apenas gerar um negócio, mas sim gerar um negócio que causará impacto social positivo, como pode ser observado na fala dos fundadores do NS7 e do NS1.

NS7 - "ele veio para o Brasil com esse sonho de abrir uma empresa para ajudar a mudar a saúde no mundo e aí a gente se conheceu. A gente acabou entrando nessa aventura."

NS1 - "eu quero trabalhar com alimentação, porque eu venho de uma família muito bem de vida, meu pai é médico, nós somos classe média, estudei em escola boa, faculdade pública e o que eu aprendi sobre o meu corpo, sobre a minha alimentação nesses dois anos, eu não tinha a menor ideia. Se eu que tenho acesso a tudo, não tenho a menor ideia, imagina quem não tem, quem está anos luz no bloco aí de educação, quanto essa pessoa está sabendo sobre a saúde dela? E aí eu falei, ah, e quero trabalhar com isso."

Autodenominados privilegiados por serem parte da classe média alta social brasileira e por terem estudado em universidades nacionais e internacionais renomadas, estes empreendedores são pessoas intrigantes a serem observadas, à medida que estão mudando a visão burguesa de mundo, deixando o destaque para pesquisar as suas percepções de mundo, e por qual razão estes estão buscando propósito de vida ao ajudar os outros ao invés de gerar apenas o lucro pelo lucro, dinheiro para manter e fazer crescer seus patrimônios.

Todos os entrevistados atualmente operam exclusivamente nestes negócios sociais que fundaram, e estão buscando crescer e aprender com os exemplos de outros negócios sociais pelo mundo. Iniciam seus negócios com base em pesquisas, como no caso do NS6. 
NS6- "minha esposa, ela é artista também, ela sempre falava que eu devia criar um brinquedo, mexer com brinquedos e nunca consegui materializar isto...quando meu filho nasceu, em 2013, eu, por conta daquelas manifestações nas ruas, eu tava bem na maternidade...E aí foi neste momento que comecei a pesquisar sobre relatos, sobre o que seria este brinquedo, o que seria este equipamento, qual seria a plataforma. Aí, eu fui pesquisando, escrevendo texto, lendo e aí aconteceu."

Inicialmente a maioria dos empreendedores entrevistados continuou atuando em seus empregos anteriores a ideia da fundação do negócio social. Eles inicialmente combinaram as duas tarefas a executar, mantendo seus custos com o emprego, a medida em que compreendia e fazia crescer os seus negócios sociais, e sempre com a preocupação sobre a autossustentabilidade financeira deste novo negócio. É arriscado, mas como eles acreditam na ideia central e estão investindo seu capital e tempo, conseguem em no máximo dois anos migrar e atuar apenas no seu próprio negócio. Percebe-se que resolver um problema social é uma oportunidade que está gerando lucro para estes negócios e podem servir de inspiração para muitos outros negócios que ainda nem estão no imaginário da sociedade.

NS1 - " ele (o sócio) foi procurar um curso de negócios sociais, na época na ESPM, e aí ele fez este curso. E ele é uma pessoa que não veio muito no mundo para brincadeira, então, o TCC do curso para ele não era só um TCC, ele foi criar uma empresa, tirar do papel e essa empresa já era os primórdios do NS1, que era focado inicialmente em produção de comida. Então a ideia era produzir comida, para abastecer os prédios que recebessem as hortas."

Mas estes empreendedores também enfrentam a dificuldade do pioneirismo, por terem ideias muitas vezes inovadoras, os negócios mudam muito ao longo tempo e vão crescendo e se ajustando. A oportunidade também é vista como fazer aquilo que gosta aliado a mudança social almejada, e estão comumente atreladas às experiências e necessidade familiares ou experiências de empregos anteriores dos empreendedores.

NS7 - "o pai e a mãe dele (sócio) são médicos na Bélgica e o pai dele é uma referência na cirurgia cardiovascular na Bélgica, na Europa como um todo. Na Europa irradia ali Oriente Médio, norte da África. É uma referência e ele (sócio) sempre conviveu muito com esse segmento de saúde, mas ele não gostava. Por mais que ele tenha dois irmãos que são médicos, ele nunca gostou. Ele sempre gostou de tecnologia."

Aliar as experiências pessoais e profissionais, o network, a formação e a mudança social por meio do impacto positivo é o que estes empreendedores tem observado como oportunidade. NS7 - "muito mais do que o negócio, que é que nem eu te falei, a gente tem um objetivo que é mudar a saúde no mundo. Se a gente, se tudo der certo, a gente vai ajudar as pessoas, ajudar as pessoas que moram longe, que tem dificuldade a ter acesso a saúde."

\section{30 acesso a capital e financiamento}

Indicada pela literatura a dificuldade em conseguir financiamento, seja em empresas sociais ou puramente comerciais, este é um problema da fase da viabilidade e da credibilidade do negócio (Lumpkin et al., 2013). Para passar por processos de aceleração e incubação, os negócios sociais pesquisados já haviam passado por algumas fases e problemas sozinhos, antes 
de procurar ajuda especializada. Inclusive, vale ressaltar que a maioria desses negócios passaram por mais de uma incubadora e aceleradora até encontrar o ponto de equilíbrio financeiro. Existe hoje uma série de negócios sociais que estão voltadas à capacitação (incubadoras) e à busca por investimentos (aceleradoras) para este tipo de empreendimento.

Os negócios sociais estudados se utilizam de espaços pequenos ou compartilhados, por ser Startups possuem equipes enxutas, e geralmente utilizam-se da tecnologia a seu favor, trabalhando muitas vezes em ambiente on line, remotamente, sem necessidade de gastos outros como transporte, alimentação e aluguel ou aquisição de um espaço para uso em tempo integral, o que viabiliza a sua fundação, mas não garante a sua continuidade.

Nenhum dos entrevistados apontou o acesso a capital ou financiamento como um antecedente facilitador na geração do negócio social. Assim como o NS7, muitos iniciaram com capital próprio.

NS7: "nos primeiros três anos, a gente foi totalmente bootstrap, entendeu? O ES7S tinha um dinheiro que ele juntou. Ele tinha algum dinheiro, eu tinha algum caixa e a gente começou. Devagar."

Muito pelo contrário, normalmente estes negócios iniciaram com capital próprio, frutos de empregos formais que resultaram em demissão e com o uso do FGTS foram criados este tipo de negócio com missão social, mas que já nasceram buscando autossustentabilidade e lucratividade.

Como os empreendedores estão atentos e se inscrevem em diversos concursos e premiações direcionados aos negócios sociais, alguns deles conseguem ser acelerados ou ganham prêmios em dinheiro para investir, ampliar ou melhorar o negócio, como foi o caso do NS7.

NS7: "E a gente foi ter o primeiro investimento acho que foi em 2015, que a gente teve investimento de um grupo europeu. Por isso que a gente voltou com o headquarter para a Bélgica. O investimento foi bem maior. Acho que foram 300 mil euros, 400 mil euros, entendeu?"

Alguns empreendedores não querem ser acelerados e não abrem o capital de sua empresa para investimentos por não se sentirem preparados, ou seja, ainda não estão em uma fase de maturação suficiente para receber grandes investimentos, e também não querem sócios opinando sobre a sua atuação.

NS3 - "Mas a ideia é, não tenho vontade de abrir para capital, até uma loucura, porque eu decidi me posicionar como NS3, sem ter um real, então eu brinco que quem vai ser meu capital de giro? Vai ser o Itaú, com cheque especial."

Mas a maioria dos entrevistados assume o risco e investe o capital próprio, apontando, portanto, a necessidade de políticas específicas de financiamento na área, pois isso viabilizaria a proliferação desse tipo de negócio.

\subsection{Várias partes interessadas, os stakeholders}

Apontado na literatura como um fator crítico de sucesso, os stakeholders, cuja definição é "[...] qualquer grupo ou pessoa cujos interesses podem afetar ou ser afetados pelas realizações dos objetivos de uma organização" (Freeman, 1984, p. 46), são pontos observáveis quando falamos em antecedentes, pois a eficácia de uma organização também é medida por sua habilidade de satisfazer aqueles que têm algum tipo de vínculo com o negócio. 
Os stakeholders quase não aparecem na fala dos entrevistados como antecedente observado da $\mathrm{OE}$, ou seja, mesmo que fundamentais, os stakeholders ficam em segundo plano perante a motivação e a oportunidade de gerar impacto social positivo. Nem mesmo o governo e os clientes foram mencionados com antecedente relevantes da OE para estes NS.

NS1 - "Os mais importantes é, bom, o cliente, o público final, que no nosso caso já são 2 stakeholders, o cliente, o corporativo e no caso de comunidade, sempre vai ser o cliente...A gente não considera o governo como stakeholder chave para gente hoje...falamos muito de conseguir fazer uma pressão de políticas públicas, melhorar a alimentação, a merenda escolar e muitas coisas estão na nossa pauta, o governo não é tão chave. A mídia tem papel fundamental na nossa história, porque a gente acaba saindo na mídia por uma geração espontânea, aí isso acaba tendo um retorno muito grande."

É claro que o cliente é o foco, mas antes de iniciar o negócio eles não procuraram manter contato com o cliente e sim buscaram solucionar o problema social. Por vezes, foi dito que talvez inicialmente o usuário não compreenda a utilidade do serviço, ou seja, a oportunidade se reforça pelo conhecimento dos empreendedores sobre os problemas sociais e as lacunas existentes em termos de serviços e produtos nas áreas que decidiram atuar.

Os negócios sociais não foram fundados buscando responder às expectativas dos stakeholders, e há por parte destes empreendedores dificuldades em ter uma visão mais ampla em relação a como estes afetam e são afetados em seu desempenho organizacional.

\section{Considerações Finais}

Com o presente artigo buscou-se caracterizar modelos e práticas estabelecendo quais os antecedentes da orientação empreendedora estão presentes e em qual intensidade para assim conseguir estabelecer ações efetivas. Atualmente existem poucos estudos voltados à compreensão dos antecedentes que podem ser os propulsores ou facilitadores de inciativas empreendedoras, e conhecendo essas relações é possível tomar ações estratégicas junto à futuros empreendedores. Portanto, os antecedentes da $\mathrm{OE}$ em negócios sociais que este estudo destaca são a oportunidade e a missão social, simultaneamente.

Esta pesquisa aponta que as situações que motivaram a criação dos negócios sociais estudados estão relacionadas às necessidades de participação e de contribuição social por parte dos fundadores. O principal objetivo desses empreendimentos ainda é gerar impacto positivo na sociedade. Situação de violência social, pobreza em abundância, fome, miséria e guerras pelo mundo são propulsoras dessas iniciativas sociais, que fazem com que esses empreendedores se sintam incomodados por terem o conhecimento, a formação necessária, e até mesmo condições financeiras para poder ajudar na mudança social. Além disso, tais iniciativas são consideradas por eles prazerosas, gratificantes e com propósito, ou seja, dão sentido à vida desses fundadores.

Interessante também notar que os produtos e serviços ofertados não servem apenas a uma população carente ou excluída, mas buscam contribuir para a qualidade de vida da população em geral. São negócios na área da saúde para facilitar a vida das pessoas e comunicar sobre doenças, epidemias e procedimentos, assim como encontrar profissionais médicos que possam ajudar; são mudanças no espaço urbano por meio de infraestrutura para tornar mais educativo e aprazível espaços como praças e escolas públicas; são as mudanças na alimentação
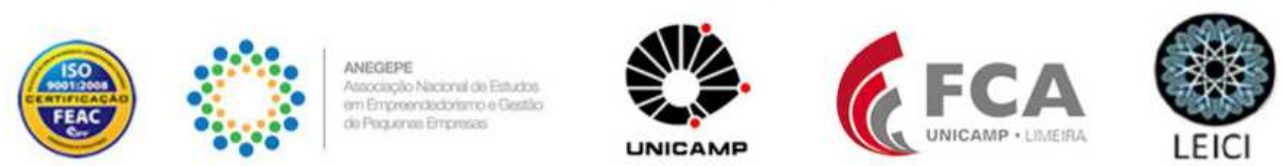
e na forma de pensar essa nutrição em centros urbanos sem espaço para cultivo, levando essa ideia saudável para grandes empreendimentos, criando hortas para funcionários e para alunos de escolas, mostrando novas possibilidades de cultivo no alto de prédios ou nas paredes das casas; são formas de pagamento e acesso ao capital de maneira diversa e inclusiva, confiando e permitindo crédito a quem não possui renda fixa, mas tem necessidades e desejos de consumo; é a preocupação de maneira geral com tecnologia e conhecimento para gerar, capacitar, melhorar e manter os negócios sociais.

Os negócios sociais não têm foco no público de baixa renda, o foco principal é na mudança social, independente da renda ou nível social, e isso sim é de interesse de todos: viver em uma sociedade mais inclusiva e participativa é um dever daqueles que possuem o poder, aqui considerado o conhecimento, a informação e a formação como o maior poder de mudança existente.

As limitações do estudo se apresentam em virtude do tamanho da amostra utilizada e da impossibilidade de generalização dos resultados ou extrapolação para todos os tipos de negócios sociais. Como indicação de pesquisas futuras, sugere-se observar os antecedentes dos negócios sociais e a Orientação Empreendedora do ponto de vista de processos, sendo as suas 5 dimensões (inovatividade, proatividade, assunção de riscos, autonomia e agressividade competitiva) analisadas e caracterizadas buscando compreender como compõem os resultados de um negócio social, e também verificar como esses antecedentes da OE afetam os resultados do negócio, auxiliando no desafio da autossustentabilidade e geração de dividendos para manter, ampliar e reproduzir esse tipo de empreendimento em outras regiões do País.

\section{Referências}

Barki, E., Comini, G., Cunliffe, A., Hart, S., \& Rai, S. (2015). Social entrepreneurship and social business: Retrospective and prospective research. Revista de Administração de Empresas, 55(4), 380-384.

Boni, V., \& Quaresma, S. J. (2005). Aprendendo a entrevistar: como fazer entrevistas em Ciências Sociais. Em Tese, 2(1), 68-80.

Bourdieu, P. (1999). A miséria do mundo. Tradução de Mateus S. Soares. $3^{a}$ edição. Petrópolis: Vozes.

Comini, G. M. (2011). "Mapa de Soluções Inovadoras - Tendências de empreendedores na construção de negócios sociais e inclusivos" realizado em parceria com a Ashoka .Recuperado em 23 de Agosto de 2016 em : http://www.ruscheleassociados.com.br/pdf/panorama2.pdf Cooley, L. (1990). Entrepreneurship training and the strengthening of entrepreneurial performance. Final Report. Contract No. DAN-5314-C-00-3074-00. Washington: USAID.

Covin, J. G., \& Slevin, D. P. (1991). A conceptual model of entrepreneurship as firm behavior. Entrepreneurship theory and practice, 16(1), 7-25.

Covin, J. G., \& Lumpkin, G. T. (2011). Entrepreneurial orientation theory and research: reflections on a needed construct. Entrepreneurship Theory and Practice, 35(5), 855-872.

Creswell, J. W. (2010). Projeto de pesquisa métodos qualitativo, quantitativo e misto. In Projeto de pesquisa métodos qualitativo, quantitativo e misto. Artmed. 
Dacin, P. A., Dacin, M. T., \& Matear, M. (2010). Social entrepreneurship: Why we don't need a new theory and how we move forward from here. The academy of management perspectives, 24(3), 37-57.

Eisenhardt, K. M. (1989). Building theories from case study research. Academy of management review, 14(4), 532-550.

Filion, L. J. (1993). Visão e relações: elementos para um metamodelo empreendedor. Revista de Administração de Empresas, 33(6), 50-61.

Filion, L. J. (2000). Empreendedorismo e gerenciamento: processos distintos, porém complementares. Revista de Administração de Empresas, 40(3), 8-17.

Freeman, R. E. (2010). Strategic management: A stakeholder approach. Cambridge university press.

Gartner, W. B. (1988). "Who is an entrepreneur?" is the wrong question. American journal of small business, 12(4), 11-32.

Hair, J. F. (2007). Research methods for business.

Hornsby, J. S., Naffziger, D. W., Kuratko, D. F., \& Montagno, R. V. (1993). An interactive model of the corporate entrepreneurship process. Entrepreneurship Theory and Practice, 17(2), 29-37.

Keh, H. T., Nguyen, T. T. M., \& Ng, H. P. (2007). The effects of entrepreneurial orientation and marketing information on the performance of SMEs. Journal of business venturing, 22(4), 592-611.

Li, Y. H., Huang, J. W., \& Tsai, M. T. (2009). Entrepreneurial orientation and firm performance: The role of knowledge creation process. Industrial marketing management, 38(4), 440-449.

Lumpkin, G. T., \& Dess, G. G. (1996). Clarifying the entrepreneurial orientation construct and linking it to performance. Academy of Management Review, 21(1), 135-172.

Lumpkin, G. T., Moss, T. W., Gras, D. M., Kato, S., \& Amezcua, A. S. (2013). Entrepreneurial processes in social contexts: how are they different, if at all? Small Business Economics, 40(3), 761-783.

Mair, J., \& Marti, I. (2006). Social entrepreneurship research: A source of explanation, prediction, and delight. Journal of world business, 41(1), 36-44.

Mansfield, R. S., McClelland, D. C., Spencer, L. M., \& Santiago, J. (1987). The identification and assessment of competencies and other personal characteristics of entrepreneurs in developing countries. Final Report: Project, (936-5314).

Martens, C. D. P., \& Freitas, H. (2010). Orientação empreendedora nas organizações e a busca de sua facilitação. Gestão. Org-Revista Eletrônica de Gestão Organizacional, 6(1).

McClelland, D. C. (1987). Characteristics of successful entrepreneurs. The journal of creative behavior, 21(3), 219-233.

McClelland, D. C. (1962). Business drive and national achievement. Harvard Business Review, 40(4), 99-11

Miller, D. (1983). The correlates of entrepreneurship in three types of firms. Management science, 29(7), 770-791.

Morris, M. H., Webb, J. W., \& Franklin, R. J. (2011). Understanding the manifestation of entrepreneurial orientation in the nonprofit context. Entrepreneurship Theory and Practice, $35(5), 47-69$. 
Muñoz, P., \& Kibler, E. (2015). Institutional complexity and social entrepreneurship: a fuzzyset approach. Journal of Business Research.

Naldi, L., Nordqvist, M., Sjöberg, K., \& Wiklund, J. (2007). Entrepreneurial orientation, risk taking, and performance in family firms. Family business review, 20(1), 33-47.

Petrini, M., Scherer, P., \& Back, L. (2016). Business model with a social impact. Revista de Administração de Empresas, 56(2), 209-225.

Rosolen, T., Tiscoski, G. P., \& Comini, G. M. (2014). Empreendedorismo social e negócios sociais: Um estudo bibliométrico da produção nacional e internacional. Revista Interdisciplinar de Gestão Social, 3(1).

Ross, J. E. (1987) Intrapreneurship and Corporate Culture. Industrial Management, v. 29, n. 1, p. 22-25,

Rúdio, F. V. (1986). Introdução ao projeto de investigação científica. Petrópolis: Editora Vozes. Short, J. C., Ketchen Jr, D. J., Combs, J. G., \& Ireland, R. D. (2010). Research methods in entrepreneurship: Opportunities and challenges. Organizational Research Methods, 13(1), 615.

Sathe, V. (1989). Fostering entrepreneurship in the large, diversified firm. Organizational Dynamics, 18(1), 20-32.

Stevenson, H. H., \& Jarillo, J. C. (1990). A paradigm of entrepreneurship: entrepreneurial management. Strategic Management Journal, 11(5), 17-27.

Wortman, M. S. (1986). A unified framework, research typologies, and research prospectuses for the interface between entrepreneurship and small business. The art and science of entrepreneurship, 273-331.

Wiklund, J., \& Shepherd, D. (2003). Knowledge-based resources, entrepreneurial orientation, and the performance of small and medium-sized businesses. Strategic management journal, 24(13), 1307-1314.

Yunus, M. (2007). Creating a world without poverty: Social business and the future of capitalism. PublicAffairs.

Yunus negócios sociais (2016) O que são negócios sociais. Recuperado em 10 de Junho de 2016 de http://www.yunusnegociossociais.com/\#!o-que-so-negcios-sociais/csrd

Zahra, S. A., \& Covin, J. G. (1995). Contextual influences on the corporate entrepreneurshipperformance relationship: A longitudinal analysis. Journal of business venturing, 10(1), 43-58. 